\title{
OUTCOMES OF CORTICOSTEROID INJECTION AND PERCUTANEOUS RELEASE IN TREATMENT OF TRIGGER FINGER AT TERTIARY HOSPITAL OF EASTERN NEPAL
}

\author{
Mithilesh Kumar Gupta ${ }^{1 *}$, Ajay Chaudhary ${ }^{1}$, Ajay Mahato $^{1}$
}

\begin{abstract}
Affiliation
1. Lecturer, Department of Orthopedic, Birat Medical College and Teaching Hospital, Nepal
\end{abstract}

\section{ARTICLE INFO}

Received : 28 January, 2021

Accepted : 05 July, 2021

Published : 04 November, 2021

(C) Authors retain copyright and grant the journal right of first publication with the work simultaneously licensed under Creative Commons Attribution License CC - BY 4.0 that allows others to share the work with an acknowledgment of the work's authorship and initial publication in this journal.

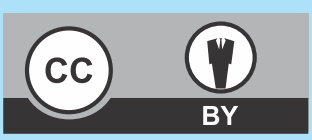

ORA 249

DOI: https://doi.org/10.3126/bjhs.v6i2.40309

* Corresponding Author

Dr Mithilesh Kumar Gupta Lecturer

Department of Orthopedic

Birat Medical College and Teaching Hospital, Nepal

Email: rdpgupta@gmail.com

ORCID: https://orcid.org/0000-0003-2824-2055

\section{Citation}

Mithilesh Kumar Gupta, Ajay Chaudhary, Ajay Mahato. Outcomes of Corticosteroid Injection and Percutaneous Release in Treatment of Trigger Finger at Tertiary Hospital of Eastern Nepal. BJHS 2021;6(2)15. 1449-1453.

\section{ABSTRACT}

\section{Introduction}

Trigger finger or stenosing tenosynovitis is a common cause of painful fingers and thumb that result in painful triggering, snapping or locking of fingers on flexion and extension of involved digit. Available treatment options for this condition are NSAID, splints, intralesional steroid injection, percutaneous release and open release of tendon sheath.

\section{Objectives}

To study the clinical and functional outcomes and complications of corticosteroid injection and percutaneous release in management of trigger finger.

\section{Methodology}

In this prospective study, sixty patients who presented with Grade 2 to Grade 3 trigger finger were placed into two groups. Group A(30 patients) were treated with intralesional steroid (40 mg of methylprednisolone) injection. Group B (30 patients) underwent percutaneous surgical release of affected tendon sheath. Both group of patients were treated in outpatient department. Patients of both groups were then asked to follow on scheduled time interval of twoweek, six-week, three-months and six-months of period and their progress were recorded.

\section{Results}

The baseline VAS score before intervention in group A (5.82) and group B (6.12) was statistically significant. In group B there was significant improvement of VAS score till 6 months of follow up. However, in group A there was significant improvement of VAS score by 3 months of follow-up, but by end of 6 months it again raised to 2.14. Yet it was far better than baseline VAS score.

\section{Conclusion}

In our study both corticosteroid injection and percutaneous trigger finger release were found to be much effective in management of trigger finger.

\section{KEY WORDS}

Trigger finger, percutaneous release, corticosteroid injection 


\section{INTRODUCTION}

Entrapment of flexor tendon of fingers, also known as trigger finger or stenosing tenosynovitis is a common tendinopathy and was first described by Notta in $1851 .{ }^{1}$ This entrapment of flexor tendon is frequently associated with pain on movement and later results in triggering, snapping or locking of involved digit on finger flexion.

The flexor tendons of fingers are enveloped by a doublewalled connective tissue cylindrical sheath. These flexor tendon sheath are held in place around tendon by three cruciform (C1-C3) and five annular pulleys ( A1-A5).This triggering of finger is caused by mismatch between the size of tendon and its sheath, and is most probably due to hypertrophy of the first annular pulley(A1). ${ }^{2}$

This hypertrophied $A 1$ pulley results in narrow fibro-osseous canal in which now flexor tendon excursion with difficulty and causes painful triggering in fingers. When continued, the patient tends to avoid a painful trigger finger, resulting in a development of secondary proximal interphalangeal flexion contracture. ${ }^{3}$

The lifetime prevalence of trigger finger among nondiabetics is approximately $2.6 \%$. It commonly affects digits of dominant hand. Middle aged women are most affected, and thumb followed by ring and middle fingers are most involved digits. Male to female ratio is 1:6 and right to left ratio is about $3: 2{ }^{4}$

It has two incidence peaks in life. The first peak is among children less than 8 years age, and the second peak in the fifth and sixth decade of life. Trigger finger in children below 10 years old predominantly have changes in tendon itself as a nodule formation whereas in adults it is the tendon sheath to be involved predominantly. In majority etiology of trigger finger are primary(idiopathic) whereas a small population has secondary cause where triggering is secondary to amyloidosis, rheumatoid arthritis, diabetes mellitus, direct trauma to tendon or tendon sheath. ${ }^{5}$

Various treatment methods are available including short term oral NSAIDs, various splints, intralesional steroid injections, percutaneous release and open release of tendon sheath. Oral NSAIDs and splints have high recurrence rates. Intralesional steroid injections has good results in single digit and early involvement. ${ }^{6-8}$ Percutaneous release of A1 pulley can also be done safely with good outcomes for fingers and thumb. ${ }^{9-14}$ Open surgical release of A1 pulley is indicated for failure of conservative treatments and for recurrent cases, but has high complications such as infections, stiffness, scar tenderness, digital (radial) nerve injury, bowstringing. ${ }^{15-17}$

As there are various treatment methods available, the aim of our study is to assess the clinical and functional outcomes of intralesional corticosteroid injections and percutaneous release in trigger finger.

\section{METHODOLOGY}

This prospective study was carried out at the outpatient department of orthopedics, at Birat medical college teaching hospital, Biratnagar, from February 2020 to January 2021. The study was approved by the institutional ethical review committee. A clinical diagnosis of trigger finger was defined as a history of triggering or locking of a finger with or without pain and tenderness or swelling at the A1 pulley. Inclusion criteria were - any patient above 18 years of age, trigger finger with Quinnell ${ }^{18}$ grade 2-3, patient giving informed consent. Exclusion criteria were- age less than 18 years, uncontrolled diabetes mellitus, coagulation disorder, fixed flexion contracture, patient who received any form of treatment for trigger finger prior to participation in this study.

Table A: Quinnell grading for trigger finger. ${ }^{18}$

- Grade 0 Mild crepitus in non-triggering finger

- Grade 1 No triggering but uneven finger movement

- Grade 2 Triggering is actively correctable

- Grade 3 Usually correctable passively by other hand

- Grade 4 The finger is locked in flexion

All patients with trigger finger fulfilling both inclusion and exclusion criteria, were included in our study until the planned number of 60 patients were achieved. The sample size was obtained after calculations, assuming alpha 0.05 and power 80 (beta 0.20). Those patients were divided into two groups. Group A included 30 patients who were treated with intralesional steroid injection. Group B also included 30 patients and they were treated with percutaneous release of trigger finger. Before any intervention all patients were examined clinically for recording the number of digits involved, side, Quinnell grading and baseline visual analogue score (VAS). All patients included were also investigated for complete hemogram, platelet counts, bleeding profile and random blood sugar.

For intralesional injection, the palmar skin surface was cleaned with povidone solution and then wiped with methyl spirit. A 26-gauge needle was inserted directly into the flexor tendon at level of A1 pulley, confirmed by detecting the movement of needle with flexion and extension of finger. The needle was then slightly withdrawn until there was no movement of needle with finger flexion and extension. At this point $40 \mathrm{mg}$ of methylprednisolone was injected.

Percutaneous trigger finger release was done as described by Bain et.al. ${ }^{19}$ and Cihantimur et.al. ${ }^{20}$ The proximal edge of A1 pulley was identified and marked; fingers were then hyperextended at metacarpophalangeal joint. This displaces digital neurovascular structures to fall away on either side of the tendon. An 18-gauge needle was then inserted directly into the tendon at the proximal edge of A1 pulley. Position of the needle in the tendon was confirmed with simultaneous movement of the needle with finger flexion. Needle was then gradually withdrawn until needle movement disappeared with finger flexion. The A1 pulley was cut by longitudinal movement of needle tip. Usually cutting of A1 pulley produces a grating sensation, loss of this grating sensation indicates complete release of A1 pulley. This is also confirmed by asking patients to actively extend and flex their finger, absence of triggering then confirms 
complete release of A1 pulley. Patient was then discharged with small dressing for a day.

Patients of both groups were then asked to follow a scheduled time interval of two-week, six-week, threemonths and six-months of period and their progress was recorded. Their outcome was measured by $-100 \mathrm{~mm}$ Visual Analog Scale for pain, adverse reaction, recurrence or presence of continuous triggering.

Statistical analysis was done with SPSS version 20. Normally distributed continuous variables were compared by student's t test. Chi-squared test and Fisher's exact test were used to compare nominal categorical data between the groups. Values of $\mathrm{P}<0.05$ were considered statistically significant.

\section{RESULTS}

In our study patients were in the age group of 29 years to 58 years of age group. Most of the patients affected were 41-50 years of age (33.3\%), followed by $51-60$ years of age (1.66\%). Group wise comparison of their distribution was as shown in Figure 1.

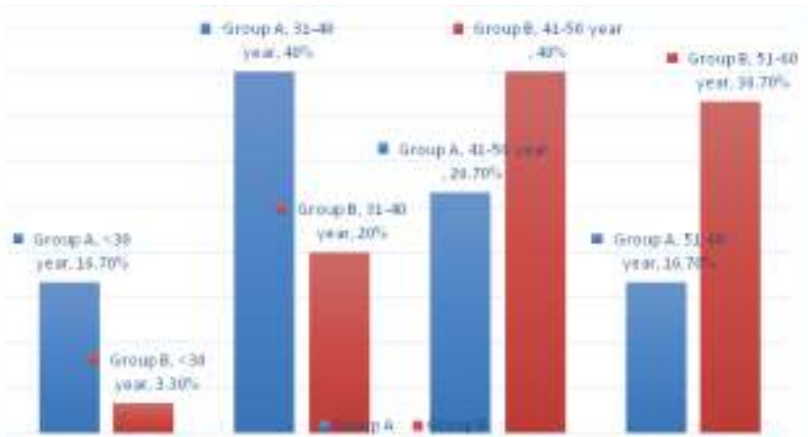

Figure 1: Distribution of age between Group A and Group B

Total number of male patients involved in group $A$ was $14(46.66 \%)$, and in group B was $13(43.33 \%)$. Similarly, the total number of female patients involved in Group A was 16(53.33\%), and in Group B was 17(56.66\%). Right hand was affected more in both groups, $28 / 30$ in group $A$ and $26 / 30$ in Group B.

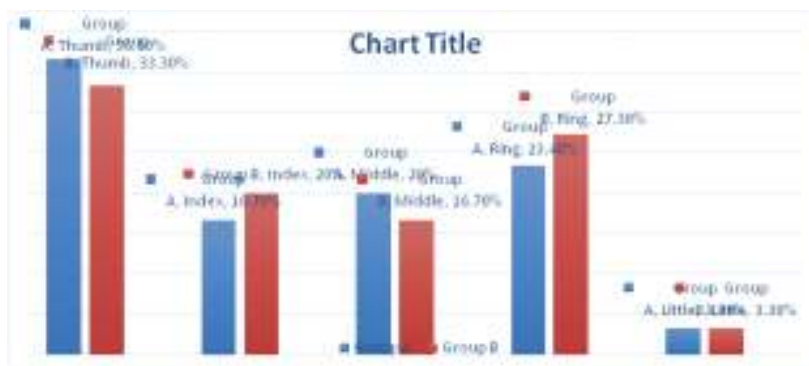

Figure 2: Distribution of sex in both groups

After intervention of both groups there was significant improvement in VAS score in patients of group A as well as VAS score of Group B patients at every follow up till 6 months of period $(p<0.001)$.

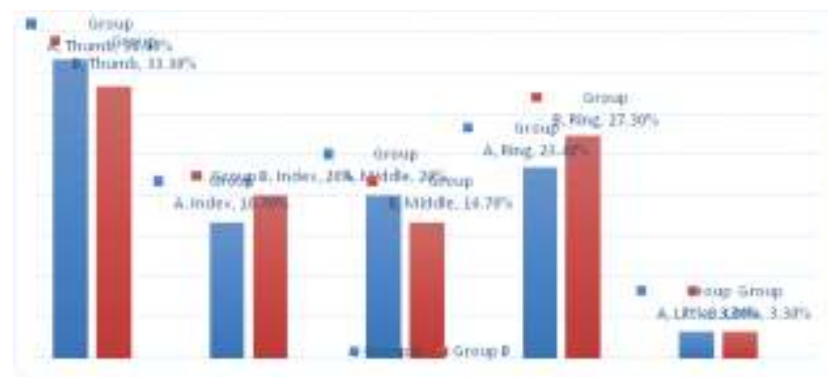

Figure 3: Distribution Right and Left hand in both Groups

Among all the involved patient's thumb was the most affected digit (36.66\%), followed by ring finger (21.66\%), Little finer was least affected one (3.33\%). Distribution of involved digits in both groups were as shown in figure 4.

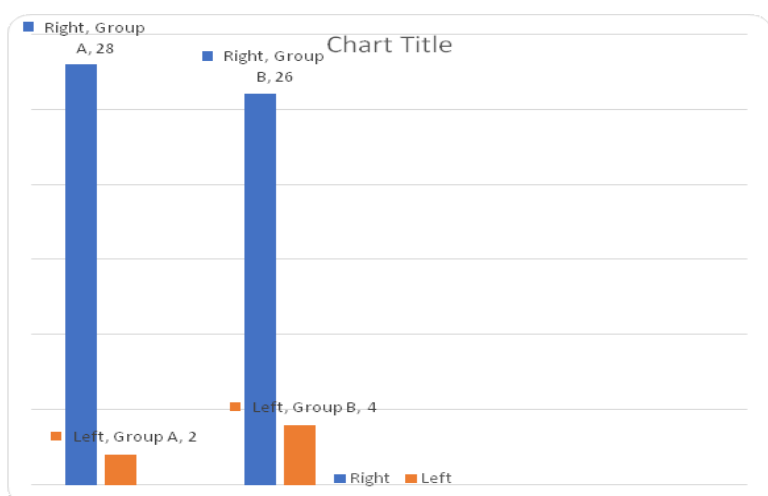

Figure 4: Distribution of fingers involved in both groups

Table 2: VAS score of both groups
\begin{tabular}{|l|c|c|c|c|c|}
\hline \multirow{2}{*}{ VAS } & \multicolumn{2}{|c|}{ Group A } & \multicolumn{2}{c|}{ Group B } & \multirow{2}{*}{ P value } \\
\cline { 2 - 6 } & Mean \pm SD & Min - Max & Mean \pm SD & Min - Max & \\
\hline Baseline & $5.82 \pm 1.32$ & $4-8$ & $6.12 \pm 0.87$ & $5-8$ & 0.360 \\
\hline 2 Week & $3.22 \pm 0.96$ & $1.50-5.50$ & $1.20 \pm 3.60$ & $0.50-2.00$ & $<0.001$ \\
\hline 6 Week & $1.86 \pm 0.89$ & $0.50-4.00$ & $0.68 \pm 0.32$ & $0.50-1.50$ & $<0.001$ \\
\hline 3 months & $1.98 \pm 1.38$ & $0.00-5.00$ & $0.54 \pm 0.71$ & $0.30-3.50$ & $<0.001$ \\
\hline 6 months & $2.14 \pm 1.62$ & $0.00-5.00$ & $0.50 \pm 0.88$ & $0.00-4.00$ & $<0.001$ \\
\hline
\end{tabular}

Table 3: Outcomes of VAS score in Quinnell grade 2 patients of both groups

\begin{tabular}{|l|c|c|c|l|c|}
\hline \multirow{2}{*}{ VAS } & \multicolumn{2}{|c|}{ Group A } & \multicolumn{2}{c|}{ Group B } & \multirow{2}{*}{ P value } \\
\cline { 2 - 6 } & Mean \pm SD & Min - Max & Mean \pm SD & Min - Max & \\
\hline Baseline & $5.82 \pm 1.32$ & $4-8$ & $6.12 \pm 0.87$ & $5-8$ & 0.360 \\
\hline 2 Week & $3.22 \pm 0.96$ & $1.50-5.50$ & $1.20 \pm 3.60$ & $0.50-2.00$ & $<0.001$ \\
\hline 6 Week & $1.86 \pm 0.89$ & $0.50-4.00$ & $0.68 \pm 0.32$ & $0.50-1.50$ & $<0.001$ \\
\hline 3 months & $1.98 \pm 1.38$ & $0.00-5.00$ & $0.54 \pm 0.71$ & $0.30-3.50$ & $<0.001$ \\
\hline 6 months & $2.14 \pm 1.62$ & $0.00-5.00$ & $0.50 \pm 0.88$ & $0.00-4.00$ & $<0.001$ \\
\hline
\end{tabular}

Table 4: Outcomes of VAS score in Quinnell grade 3 patients of both groups

\begin{tabular}{|l|c|c|c|c|c|}
\hline \multirow{2}{*}{ VAS } & \multicolumn{2}{|c|}{ Group A (n= 14) } & \multicolumn{2}{c|}{ Group B (n=16) } & \multirow{2}{*}{ P value } \\
\cline { 2 - 6 } & Mean \pm SD & Min - Max & Mean \pm SD & Min - Max & \\
\hline Baseline & $7.74 \pm 0.89$ & $5-8$ & $6.73 \pm 0.85$ & $5-8$ & 0.129 \\
\hline 2 Week & $3.36 \pm 0.52$ & $2.84-3.88$ & $0.88 \pm 0.45$ & $0.43-1.33$ & $<0.001$ \\
\hline 6 Week & $2.94 \pm 0.50$ & $2.44-3.46$ & $1.31 \pm 0.85$ & $0.46-2.16$ & $<0.001$ \\
\hline 3 months & $3.76 \pm 0.72$ & $3.04-4.48$ & $1.43 \pm 1.11$ & $0.32-2.54$ & $<0.001$ \\
\hline 6 months & $4.24 \pm 0.59$ & $3.65-4.83$ & $1.62 \pm 1.36$ & $0.26-2.98$ & $<0.001$ \\
\hline
\end{tabular}

\section{DISCUSSION}

Flexor tenosynovitis or trigger finger is a very frequent cause of pain and triggering in digits of adults. Though it 
may involve any finger, thumb and ring finger of dominant hand are the most affected digits. ${ }^{21}$

Zyluk et al, in their study reported $37 \%$ involvement of thumb, followed by $33 \%$ involvement of ring fingers, $21 \%$ middle fingers, $8 \%$ little fingers and only $1 \%$ involvement of index finger. ${ }^{22}$ In our study also thumb was most affected digit (36.66\%), followed by ring finger (21.66\%), Little finger was least affected one (3.33\%).

In a study by Marks and Gunther the trigger finger condition was four times more prevalent in women than in male. ${ }^{23}$ In our study total number of male patients involved in group $A$ was $14(46.66 \%)$, and in group B was $13(43.33 \%)$. Similarly, the total number of patients involved in Group B was 16(53.33\%), and in Group B was 17(56.66\%).Thus male to female ratio in group $A$ was 14:13, and in group $B$ was 16:17.

Many treatment modalities have been recommended for the management of trigger finger like NSAIDs, splints, intralesional steroid, percutaneous trigger release and open surgical trigger finger release. ${ }^{6-10,15-17}$ Marks and Gunther in their study of 108 trigger finger recorded success in $92 \%$ of trigger digits with single dose of intralesional steroid injection. ${ }^{23}$ However, studies by Newport et.al. and Rhodes et.al. reported lower success rate of $55 \%$ and $45 \%$ with intralesional steroid injection when patients had symptoms of triggering for more than 6 months prior to treatment. ${ }^{24,25}$

Open surgical release has a high success rate and low recurrence rate, thus also considered the standard of treatment for trigger finger. But it also has potential complications such as painful scar, infections, bowstringing and neurovascular injuries. There are studies which have reported $26 \%$ of dissatisfaction rate with open surgical treatment of trigger finger. ${ }^{15-17}$

Lorthior in 1958 first descried percutaneous release of trigger finger. In their study they good results in all 52 patients without any neurovascular complication. ${ }^{9}$ Similarly, Leu in 1992 reported percutaneous release with a curved knife in 16 trigger fingers with high success rate. ${ }^{26}$

Eastwood et. al in 1992 was the first to report the use of 21gauge needle instead of a knife for percutaneous release. He had success rate of $94 \%$ in 35 trigger digits. ${ }^{10}$

Because of proximity of digital nerves to A1 pulley in thumb some authors recommended to avoid percutaneous release in cases where thumb is involved. ${ }^{19,20}$ However, Cihantimur et. al and Gilberts et. al claimed $100 \%$ success rate with their method of percutaneous release even in thumb. ${ }^{19,20}$

The decision of choice of treatment depends on the severity and duration of trigger finger. Salanda first outlined treatment of trigger fingers according to severity. ${ }^{18}$ It is widely accepted that Quinnell grade 0 and 1 responds well to physiotherapy, NSAIDs and splints, failure of this responds well to corticosteroid treatment. Quinnell grade 4 usually is resistant co conservative treatment and requires surgical release. Thus, the management of grade 2 and grade 3 are still subject for debate.

Our study was a prospective study of two groups which had statically comparable baseline demographic features such as age, sex, side, digits involved, duration of symptoms, grade of triggering. Our objective was to study the outcomes of both treatment modalities during and by the end of 6 months of duration.

The baseline VAS score before intervention in group $A$ (5.82) and group B (6.12) was statistically comparable. In group B there was uniform fall in VAS score till 6 months of follow up. However, in group A there was uniform fall of VAS score by 3 months of follow-up, but by end of 6 months it again raised to 2.14. Yet it was far better than baseline VAS score. In the study by Zyluk $A, 46$ digits treated with percutaneous release and 47 digits treated with corticosteroid injection had a similar fall in VAS, with mild better response in percutaneous group. $^{22}$

In this study, VAS scores by the end of 6 months were far below the baseline in both groups with both grades with statistically significant better outcome in group B compared to group $A$ throughout all follow up visits. This is like study reported by Chao et al, where at the end of one month both treatments were equally effective but by the end of 6-month assessment, patients treated with percutaneous release had slight better response, whereas those treated with steroid injection had slight deterioration. ${ }^{22}$

In Group A 1(3.33\%) patient had complain of hypopigmented skin by the $6^{\text {th }}$ week of injection which did not required any intervention except reassurance of patient. In Group B three patients $(10 \%)$ had mild skin inflammation after 2 days of percutaneous release, they were treated with oral Cefuroxime for five days, without any further complications. Saldana MJ, in their study of 31 patients treated with percutaneous release, reported similar condition two patients, treated with oral antibiotics. ${ }^{18}$

In group A total 5 patients (16.66\%) had recurrence of triggering requiring repetition of intralesional steroid injection at 3 months of follow up. No patient in group B had recurrence by the end of study. This contrasts with study by Zyluk et al, who reported $11 \%$ of recurrence rate in patients treated by steroid injection, by the end of 6 month follow up. ${ }^{22}$

\section{CONCLUSION}

To conclude both corticosteroid injection and percutaneous trigger finger release were found to be equally effective in management of trigger finger, but per cutaneous group has slight better outcome in term of VAS by the end of 6 months of follow up.

\section{RECOMMENDATION}

Based on results of our study we recommend both intralesional steroid and per cutaneous release are useful and safe for treatment of trigger finger that can be performed as outpatient department procedures. However, in terms of complication and recurrence both treatment modalities has similar response.

\section{LIMITITATION OF STUDY}

This was a prospective study conducted at a single tertiary center. The results may also vary with longer periods of follow up. 


\section{ACKNOWLEDGEMENTS}

We are thankful to all the patients who participated in our study. We also highly appreciate our statistician for helping in statistical analysis.

\section{CONFLICT OF INTREST}

No conflict of interest or funding was received for our study.

\section{REFERENCES}

1. Notta A. Recherchessurune affection particuliere des gainestendineuses de la main. Arch Gen Med 1850(24):142.

2. Sato ES, Gomes Dos Santos JB, Belloti JC, Albertoni WM, Faloppa F. Treatment of trigger finger: randomized clinical trial comparing the methods of corticosteroid injection, percutaneous release and open surgery. Rheumatology (Oxford)2012; 51:93e9. PMID:22039269

3. Makkouk $A H$, Oetgen ME, Swigart $C R$, Dodds SD. Trigger finger: etiology, evaluation, and treatme .Curr Rev Musculoskelet Med 2008;1:92e6. PMID:19468879

4. Fahey JJ, Bollinger JA. Trigger finger in adults and children. J Bone Joint Surg. 1954; 36:1200-18. PMID: 13211713

5. Bonnici AV, Spencer JD. A survey of trigger finger in adults. J Hand Surg. 1988; 13:202. PMID: 3385301

6. Kolind-Sorensen V. Treatment of trigger fingers. Acta Orthop Scandinav 1970; 41:428-432. PMID:5537268

7. Rhoades CE, Gelberman MD, Manjarris JF. Stenosing tenosynovitis of the fingers and thumb. Clin Orthop1984; 190:236-238. PMID: 6488636

8. Patel MR, Bassini L. Trigger fingers and thumb: When to splint, inject, or operate. J Hand Surg 1992;17(1):110-113. PMID: 1538090

9. Lorthioir J. Surgical treatment of trigger-finger by a subcutaneous method. J Bone Joint Surg 1958; 40A:793-795. PMID: 13549516

10. Eastwood DM, Gupta KJ, Johnson DP. Percutaneous release of trigger finger: an office procedure. J Hand Surg 1992;17A:114-117. PMID: 1538091

11. RyzewiczM,Wolf JM. Trigger digits: Principles, management, and complications. J Hand Surg 2006;31A:135-146. PMID: 16443118

12. Joy AK, Brogen AK, Wangjam K, Singh I, Bimol N, Nilachandra L. Percutaneous release of trigger fingers: Is it reserved for few surgeons? IJPMR 13, April 2002;1-4.

13. Cihantimur B, Akin S, Ozcan M. Percutaneous treatment of trigger finger. 34 fingers followed 0.5-2 years. ActaOrthopScand 1998;69 (2):167-168. PMID: 9602776
14. Cebesoy O, Karakurum G, Kose KC, Baltaci ET, Isik M. Percutaneous release of the trigger thumb: Is it safe, cheap and effective? International Orthopaedics (SICOT) 2007; 31:345-249. PMID: 16847643

15. RyzewiczM,Wolf JM. Trigger digits: Principles, management, and complications. J Hand Surg 2006; 31A:135-146. PMID: 16443118

16. Maneerit J, Sriworakun C, Budhraja N, NagavajaraP.Trigger thumb: results of prospective randomised study of percutaneous release with steroid injection versus steroid injection alone. J Hand Surg (British \& European volume) 2003;28(6):586-589. DOI: 10.106/ S0266-7681(03)00172-4

17. Carrozella J, Stern PJ, Von Kuster LC. Transection of radial digital nerve of the thumb during trigger release. J Hand Surg (Am) 1989; 14(2):198-200. PMID: 2703666

18. Saldana MJ. Percutaneous trigger finger release. Atlas Hand Clin. 1999; 4:23-37. DOI: 10.4103/2224-4018.141840

19. Bain GI, Turnbull J, Charles MN, Roth JH, Richards RS. Percutaneous A1 pulley release: A cadaveric study. J Hand Surg 1995; 20A:781-784. PMID: 8522744

20. Pope DF, Wolfe SW. Safety and efficacy of percutaneous trigger finger release. J Hand Surg 1995; 20A280-283. PMID: 7775770

21. Bonnici AV, Spencer JD. A survey of trigger finger in adults. J Hand Surg. 1988; 13:202. PMID: 3385301

22. Zyluk A, Jagielski G. Percutaneous A1 pulley release vs steroid injection for trigger digit: the results of a prospective, randomized trial. J Hand Surg Eur. 2011; 36:53-6. PMID: 20709708

23. Thorpe AP. Results of surgery for trigger finger. J Hand Surg $\mathrm{Br}$ 1988;13:199-201. PMID: 3385300

24. Newport ML, Lane LB, Stuchin SA. Treatment of trigger finger by steroid injection. J Hand Surg 1990;15:748-750. PMID: 2229972

25. Rhoades CE, Gelberman MD, Manjarris JF. Stenosing tenosynovitis of the fingers and thumb. ClinOrthop 1984; 190:236-238. PMID: 6488636

26. Lyu SR. Closed division of the flexor tendon sheath for trigger finger. J Bone Joint Surg 1992;74-B:418-420. PMID: 1587893 